\title{
Prediction of tangential force and maximum temperature generation at the tool tip using ANFIS model during CNC turning operations for an intricate shape
}

\author{
Goutam Paul*, Pritam Patra \\ Department of Mechanical Engineering, MCKV Institute of Engineering, 243 G.T. Road Liluah (N), \\ Howrah, 711204, India
}

E-mail: goutamju04@gmail.com

\begin{abstract}
In spite of vigorous research on advanced material processing and advanced manufacturing processes, the conventional processes are essential in building a country's economy till date. The disadvantage of this process is that machining industry is the most energy consuming and waste spawning industry. The main question is how the energy can be utilized in proper way such that energy consumption will be on lower side and will provide high productivity. The consumption is more whenever we concern the intricate shape of the job. The two factors that are important for the measurement of energy consumption during CNC turning of an intricate shape are tangential force and tool tip temperature generation. In the current research, experiments were conducted based on DOE by developing experiments with three factors i.e. cutting speed at four levels and feed and depth of cut at two levels corresponding to the L8 experimental array to measure maximum tangential force and temperature generation at the tool tip during CNC turning operation. Prediction of maximum tangential force and tool tip temperature during CNC turning operation has been pursued with the help of Taguchi approach. At the end, a verification test was conducted to illustrate the effectiveness of this approach.
\end{abstract}

Keywords: CNC Turning, Tangential Force, Tool Tip Temperature, L8 Orthogonal Array.

\section{INTRODUCTION}

The objectives in Indian machining industry are quite different than the other developed countries. Because of intense availability of skilled manpower, conventional machining is still being used in large quantity. Majority of workers in such a small scale industry lacks proper training and hence it is very difficult to make them understand the concepts of mathematical model and outcomes. Till date lots of the products are being developed and/or manufactured in CNC machining but sustainability assessment of a CNC turning process at small scale industry is rarely focused. Thus, there is a need of developing a simple model which will be easy to understand and can be easily incorporated in small scale industries working on CNC machining. The components of resultant force in machining process, especially the main cutting (tangential) force, is one of the main parameters providing information on machinability of materials. The machining force components are influenced by several factors such as cutting speed, feed rate, depth of cut, cutting fluids, tool geometry, and others, besides the properties of the material being machined $[1,2]$. The forces, in turn, influence cutting temperature, tool wear and life, work piece surface integrity, machining dynamics, dimension of the machine-tool structures, machining power, and others [3-6].
Material removal processes are an integral part of many manufacturing processes. It is important to study the many factors influencing these operations in order to achieve better performance with minimum energy consumption. The chip formation process occurring during metal cutting is a complicated one, involving plastic deformation, work hardening, heat generation, and tool wear. Finding a range of cutting conditions that will give maximum efficiency can help manufacturers produce in sustainable way.

In machining process, the cutting energy is mostly transformed into heat and eliminated through the chips but some of this energy increases the temperature of the tool and work piece. The main source of energy that is converted into heat is the plastic deformation at shear zone, friction in the interfaces tool/chip and tool/work piece. During the cutting process, high temperatures are generated near the tool cutting edge, and these temperatures affect greatly the tool wear rate. These temperatures, whose maximum value occurs along the tool rake face at some distance from the cutting edge [7, 8], can be estimated from measure of the thermal electromotive force of tool-work piece thermocouple during cutting process. Rajemi et. al. [9] developed a model for optimizing energy footprint of machined product. They identified critical parameters in minimizing energy use and hence reducing energy cost and environmental impact. The aim of this research work is to study the effect of varying machining 
parameters on maximum temperature generated at tool tip during CNC turning of a complex shape on Aluminum work piece using HSS tools in order to develop prediction models for these by using Taguchi analysis $\left(\mathrm{L}_{8}\right)$ [10]. The machining parameters studied are speed $(v)$, feed $(f)$, and depth of cut $(d)$. The result of the Taguchi analysis was further analysed with design of experiment (DOE) and then the data were fitted in an adaptive Neuro-Fuzzy system (ANFIS) $[11,12]$ to predict the optimum prediction of temperature generation at the tool tip during $\mathrm{CNC}$ turning operations.

\section{EXPERIMENTAL MEASUREMENTS}

PROCEDURE

AND

\subsection{Cutting tool preparation}

HSS cutting tools with 5\% cobalt (M-grade SI 6) were used with specific cutting angles, such that the tools cut orthogonally. This meant a back rake angle, side rake angle, and side cutting angle of zero degrees, resulting in a rake angle of zero degrees as well as high relief angles. The tool signature is listed below.

(i) back rake angle $=0^{\circ}$;

(ii) side rake angle $=0^{\circ}$;

(iii) end relief angle $=16^{\circ}$;

(iv) side relief angle $=21.5^{\circ}$;

(v) end cutting edge angle $=23^{\circ}$;

(vi) side cutting edge angle $=0^{\circ}$;

(vii) nose radius $=0.25 \mathrm{~mm}$

\subsection{Work material preparation}

Work piece materials have been prepared by turning from the rod of Aluminum of grade 4. The dimension of the work piece is $\emptyset 25 \times 100 \mathrm{~mm}$. The product was produced on both sides of the raw materials. The product cannot be made by mere longitudinal turning since a round shape was given in the product shape. The generated products are shown in Figure 1.

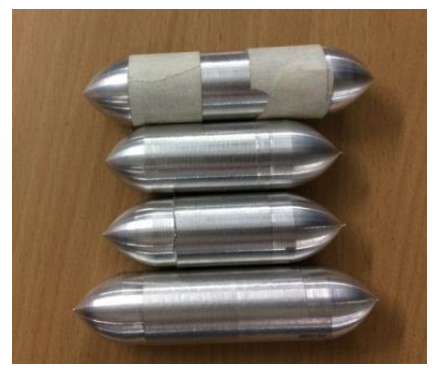

Figure 1. Photograph of the generated products (with magnification 20X)

\subsection{Experimental setup}

The experiments were performed in a $\mathrm{HYTECH} \mathrm{CNC}$ turning center (model. Nano-CNC-PC) at advanced technology lab of MCKVIE. It has $0.010 \mathrm{~mm}$ and $0.005 \mathrm{~mm}$ minimum movement along $\mathrm{X}$ direction and $\mathrm{Z}$ direction respectively. The photographs of the machine set up along with the MCU have been shown in Figure 2.

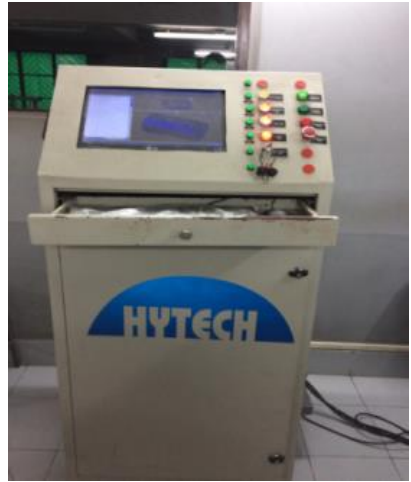

a) $\mathrm{MCU}$

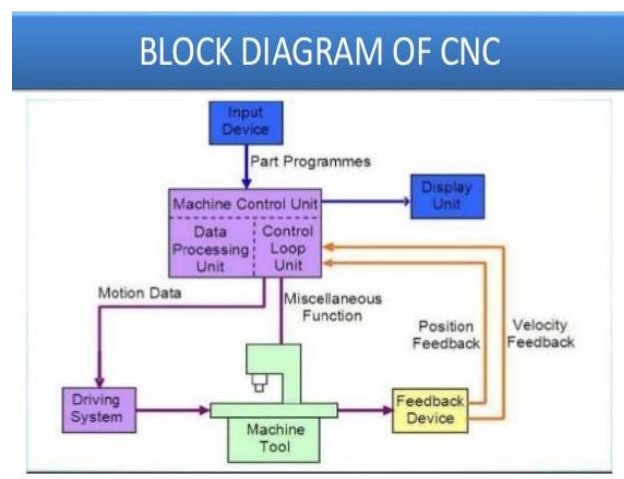

b) Block diagram

Figure 2. Experimental setup (HYTECH CNC turning center with MCU)

\subsection{Design of experiment}

Taguchi's approach provides the designer with a systematic and efficient approach for conducting experimentation to determine near optimum settings of design parameters for performance and cost. The method emphasizes pushing quality back to the design stage, seeking to design a product/process, which is insensitive to quality problems. The Taguchi method utilizes orthogonal arrays to study a large number of variables with a small number of experiments. Using orthogonal arrays significantly reduces the number of experimental configurations to be studied. The conclusions drawn from small-scale experiments are valid over the entire experimental region spanned by the control factors and their settings. This method can reduce research and development costs by simultaneously studying a large number of parameters. In order to analyze the results, the Taguchi method uses a statistical measure of performance called signal-to- noise $(\mathrm{S} / \mathrm{N})$ ratio. The $\mathrm{S} / \mathrm{N}$ ratio takes both the mean and the variability into account. The $\mathrm{S} / \mathrm{N}$ equation depends on the criterion for the quality characteristic to be optimized. After performing the statistical analysis of $\mathrm{S} / \mathrm{N}$ ratio, an analysis of variance (ANOVA) needs to be employed for estimating error variance and for determining the relative importance of various factors.

\section{(a) $\mathrm{L}_{8}$ orthogonal array}

In $\mathrm{L}_{8}$ array 8 rows represent the 8 experiments to be conducted with 3 columns at, 4 levels of one factor and 2 levels of the rest 2 factors. The matrix forms of these arrays are shown in Table 1 . Where 1, 2, 3, etc. in the table represents the level of each parameters. 
(b) Determination of $\mathrm{S} / \mathrm{N}$ ratio curve

$\mathrm{S} / \mathrm{N}$ ratio is a mathematically transformed form for quality/ performance characteristic, the maximization of which minimizes quality loss and also improves (statistically) the additive of control factor effects.

From each experimental result, $\mathrm{S} / \mathrm{N}$ value can be calculated as

$\eta=-10 \log \left[\frac{1}{n} \sum_{i=1}^{n} y_{i}^{2}\right]$

for the smaller is better type problem and for larger is better type problem.

$\eta=-10 \log \left[\frac{1}{n} \sum_{i=1}^{n} \frac{1}{y_{i}^{2}}\right]$

where $\eta$ denotes the $\mathrm{S} / \mathrm{N}$ ratio calculated from the observed or experimental values $y_{i}$ represents the experimental observed value of the $i$ th experiment, and $n$ is the number of times each experiment is repeated.

Table 1. Factors with their levels

\begin{tabular}{|c|c|c|c|c|c|}
\hline Control & \multicolumn{5}{c}{ Level } \\
Factor & 1 & 2 & 3 & 4 & Unit \\
& 500 & 1000 & 1500 & 2000 & RPM \\
$\begin{array}{c}\text { A. Cutting } \\
\text { Speed }\end{array}$ & 30 & 90 & ----- & ---- & $\mathrm{mm} / \mathrm{min}$ \\
$\begin{array}{c}\text { B. Feed Rate } \\
\text { C.DOC }\end{array}$ & 0.5 & 1.5 & ----- & ----- & $\mathrm{mm}$ \\
\hline
\end{tabular}

2.5 Maximum temperature at the tool tip measurement

Table 2. $\mathrm{L}_{8}$ orthogonal array

\begin{tabular}{|l|l|l|l|}
\hline & \multicolumn{3}{c|}{$\begin{array}{c}\text { Column No.\& Factor } \\
\text { Expt. } \\
\text { No }\end{array}$} \\
assignment & B & C \\
\hline 1 & 1 & 1 & 1 \\
\hline 2 & 1 & 2 & 2 \\
\hline 3 & 2 & 1 & 1 \\
\hline 4 & 2 & 2 & 2 \\
\hline 5 & 3 & 1 & 2 \\
\hline 6 & 3 & 2 & 1 \\
\hline 7 & 4 & 1 & 2 \\
\hline 8 & 4 & 2 & 1 \\
\hline
\end{tabular}

It is assumed that the process has orthogonal cutting geometry and the chip is sheared from the blank at an infinitely thin shear plane (i.e. primary deformation zone). The chip slides on the rake face (i.e. secondary deformation zone) with a constant average friction coefficient. The thermocouple which was used could measure from $-50^{\circ} \mathrm{C}$ to $1300^{\circ} \mathrm{C}$ with a resolution of $1^{\circ} \mathrm{C}$ and accuracy of $\pm(0.3 \%$ $\left.\mathrm{rdg}+1^{\circ} \mathrm{C}\right)$. The display unit has 3.5 digits LCD with maximum reading of 1999. During the experiment 4-foot type " $K$ " thermocouple bead probe (Teflon tape insulated).

Maximum insulation temperature $260^{\circ} \mathrm{C}$. Probe accuracy $\pm 2.2^{\circ} \mathrm{C}$ or $\pm 0.75 \%$ of reading whichever is greater. The probe was touched firmly against the tool tip during experiment to measure the temperature. The reading was taken after the reading become stable.

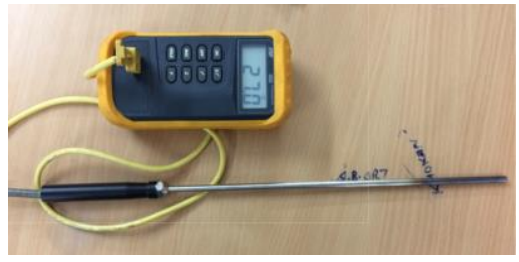

Figure 3. Thermocouple for measurement of temperature of tool tip

\section{RESULTS AND DISCUSSION}

\subsection{Analysis of main cutting force $(\mathrm{Fc})$ based on $\mathrm{S} / \mathrm{N}$ ratio curve and ANOVA table}

From the $\mathrm{S} / \mathrm{N}$ ratio curve for feed force as depicted in Figure 8 , it has been found that feed force have an increasing trend with the increase of depth of cut, feed rate and cutting speed. This is due to the fact that with increase of depth of cut, feed rate and cutting speed the tool and work interaction is more. As a result the feed force increases. From Fig 7 depicts residual plots of feed force.

Table 3. ANOVA analysis for main cutting force

\begin{tabular}{|c|c|c|c|c|c|}
\hline Factors & $\begin{array}{c}\text { D.O.F } \\
\text {. }\end{array}$ & $\begin{array}{c}\text { S.O.S } \\
.\end{array}$ & $\begin{array}{l}\text { Mean } \\
\text { Square }\end{array}$ & $\mathbf{F}$ & p \\
\hline $\begin{array}{l}\text { Regress } \\
\text { ion }\end{array}$ & 3 & 8590 & 2863.33 & 71.58 & 0.0006 \\
\hline $\mathbf{A}$ & 1 & 90 & 90.00 & 2.25 & 0.2080 \\
\hline B & 1 & 2450 & 2450.00 & 61.25 & 0.0014 \\
\hline C & 1 & 6050 & 6050.00 & 151.25 & 0.0002 \\
\hline Error & 4 & 160 & 40.00 & & \\
\hline Total & 7 & 8750 & & & \\
\hline
\end{tabular}

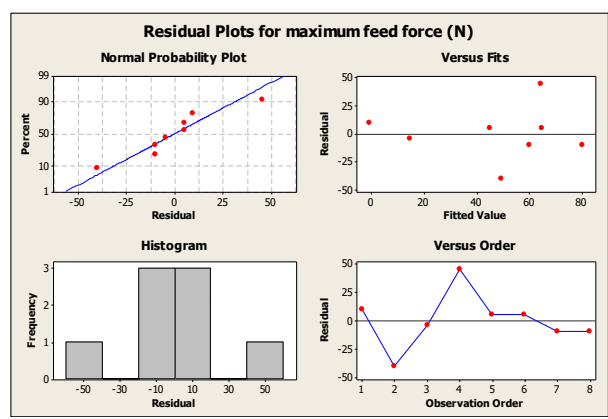

Figure 4. Residual plots for main cutting force

a Indicates the sum of squares added together to form the pooled error sum of squares shown in parentheses.

Referring to the sum of squares column in Table 3, notice that D.O.C. makes the largest contribution to the total sum of squares. Feed rate makes the next largest contribution for the response and cutting speed has very small contribution to the total sum of squares. The larger contribution of a particular 
factor to the total sum of squares, the larger the ability is of that factor to influence $\eta$. So, depth of cut and feed rate has more effect on chip thickness. For minimization of chip thickness, we have to control the depth of cut and feed rate and we have to set these two parameters very carefully.

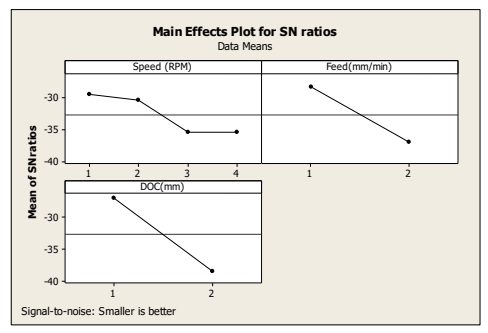

Figure 5. S/N ratio plots for main cutting force

\subsection{Analysis of $T_{\max }$ based on $\mathrm{S} / \mathrm{N}$ ratio curve and ANOVA table}

From the $\mathrm{S} / \mathrm{N}$ ratio curve of $\mathrm{T}_{\max }$ as depicted in Figure 10, $\mathrm{T}_{\max }$ has been found to have an increasing trend with the increase of depth of cut and speed of machining. This is due to the fact that with increase of cutting speed and feed rate the frictional forces increases. As a result the $\mathrm{T}_{\max }$ increases. With the increase of depth of cut the $T_{\max }$ increases because of increase of friction between the tool tip and workpiece. Figure 9, sows the residual plot of $\mathrm{T}_{\max }$.

From Table 3, it can be observed that cutting speed makes the largest contribution to the total sum of squares. The factor depth of cut makes the next largest contribution to the total sum of squares. Factor feed rate has relatively small contribution to the total sum of squares. So cutting speed and depth of cut have more effect on Tmax and other factor has less effect on the $T_{\max }$.

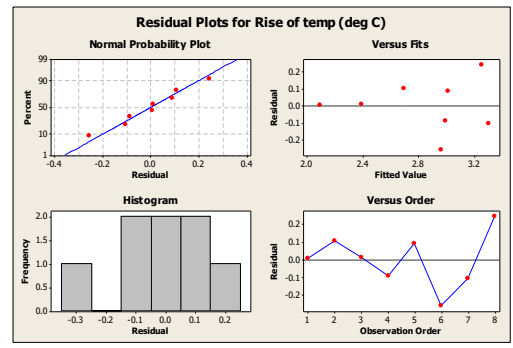

Figure 6. Residual plots for maximum rise of temperature (degree centigrade)

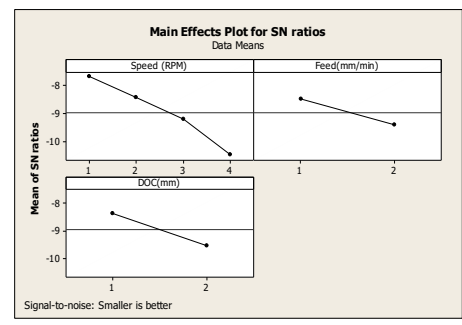

Figure 7. $\mathrm{S} / \mathrm{N}$ ratio plots for maximum rise of temp (Degree centigrade)

a indicates the sum of squares added together to form the pooled error sum of squares shown in parentheses.

\subsection{Outcomes of the analysis}

From the $\mathrm{S} / \mathrm{N}$ ration curve for feed force and Tmax the optimum parametric combinations are noted. The cutting speed, depth of cut and feed rate is shown in Table 4 below.

\subsection{Validation experiment}

To verify the proposed model another set of experiment has been carried out as shown in Table 4 It is observed from Table 5 that prediction based on additive model is quite close to the experimental observation. Prediction error in the Table 6 has been defined as follows

Table 3. ANOVA analysis for Tmax

\begin{tabular}{|c|c|c|c|c|c|}
\hline Factors & D.O.F. & S.O.S. & \multicolumn{1}{c|}{ Mean Square } & F & p \\
\hline $\begin{array}{c}\text { Regressi } \\
\text { on }\end{array}$ & $\mathbf{3}$ & $\mathbf{1 . 2 3}$ & $\mathbf{0 . 4 1}$ & $\mathbf{9 . 9 0}$ & $\mathbf{0 . 0 3}$ \\
\hline A & $\mathbf{1}$ & $\mathbf{0 . 8 7}$ & $\mathbf{0 . 8 7}$ & $\mathbf{2 0 . 9 7}$ & $\mathbf{0 . 0 1}$ \\
\hline B & $\mathbf{1}$ & $\mathbf{0 . 1 5}$ & $\mathbf{0 . 1 5}$ & $\mathbf{3 . 6 4}$ & $\mathbf{0 . 1 3}$ \\
\hline C & $\mathbf{1}$ & $\mathbf{0 . 2 1}$ & $\mathbf{0 . 2 1}$ & $\mathbf{5 . 0 9}$ & $\mathbf{0 . 0 9}$ \\
\hline Error & $\mathbf{4}$ & $\mathbf{0 . 1 7}$ & $\mathbf{0 . 0 4}$ & & \\
\hline Total & $\mathbf{7}$ & $\mathbf{1 . 4 0}$ & & & \\
\hline
\end{tabular}

Table 4. Optimum parametric combination

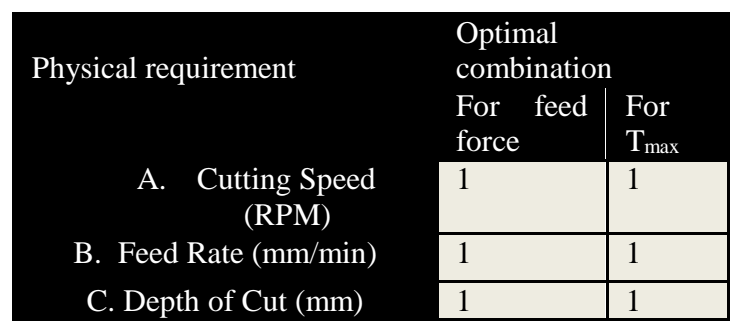

Prediction Error $(\%)=\left|\frac{\text { Exp.result }- \text { Pr edicted result }}{\text { Exp.result }}\right| \times 100$

Table 5. Verification experiment

\begin{tabular}{|c|c|c|c|c|c|}
\hline \multirow{2}{*}{$\begin{array}{l}\text { Exp. } \\
\text { No. }\end{array}$} & \multicolumn{3}{|c|}{ Control factors } & \multicolumn{2}{|c|}{ Responses } \\
\hline & $\begin{array}{l}\text { Cutting } \\
\text { Speed } \\
\text { (RPM) }\end{array}$ & $\begin{array}{c}\text { Feed } \\
\text { Rate } \\
(\mathrm{mm} / \mathrm{min})\end{array}$ & $\begin{array}{l}\text { DOC } \\
(\mathrm{mm})\end{array}$ & $\begin{array}{l}\text { Feed } \\
\text { Force } \\
(\mathrm{N})\end{array}$ & $\begin{array}{c}\text { Rise of } \\
\text { temp } \\
\text { (degree } \\
\text { C) }\end{array}$ \\
\hline 1 & 1 & 1 & 1 & 9.51 & 2.15 \\
\hline
\end{tabular}

Table 6. Prediction error calculation

\begin{tabular}{|c|c|c|c|c|c|c|}
\hline \multirow{2}{*}{$\begin{array}{l}\text { Exp. } \\
\text { No. }\end{array}$} & \multicolumn{2}{|c|}{$\begin{array}{c}\text { Experimental } \\
\text { Result }\end{array}$} & \multicolumn{2}{|c|}{ Predicted Value } & \multicolumn{2}{|c|}{$\begin{array}{l}\text { Prediction } \\
\text { Error }(\%)\end{array}$} \\
\hline & $\begin{array}{c}\text { Feed } \\
\text { Force } \\
(\mathrm{N})\end{array}$ & $\begin{array}{c}\text { Rise of } \\
\text { temp } \\
\text { (degree } \\
\text { C) }\end{array}$ & $\begin{array}{c}\text { Feed } \\
\text { Force } \\
(\mathrm{N})\end{array}$ & $\begin{array}{c}\text { Rise of } \\
\text { temp } \\
\text { (degree } \\
\text { C) }\end{array}$ & Feed Force & $\begin{array}{l}\text { Rise } \\
\text { of } \\
\text { temp }\end{array}$ \\
\hline 1 & 10 & 2.1 & 9.51 & 2.15 & 4.9 & 2.4 \\
\hline
\end{tabular}


It is clear that the data agree very well with the predictions. Therefore, the optimum settings given in Table 5 may be adopted and implemented accordingly.

\section{PREDICTION OF OPTIMUM TMAX BY ANFIS APROACH}

The adaptive network-based fuzzy inference system (ANFIS) is a Takagi-Sugeno based fuzzy inference system proposed by Jang [7]. Assuming a fuzzy rule with two inputs and a single output, the first order Takagi-Sugeno if-then rules can be written as follows.

Rule 1. If $\mathrm{x}$ is $\mathrm{A} 1$ and $\mathrm{y}$ is $\mathrm{B} 1$ and $\mathrm{z}$ is $\mathrm{C} 1$ then $\mathrm{F} 1=\mathrm{p} 1 \mathrm{x}+\mathrm{q} 1$ $\mathrm{y}+\mathrm{r} 1 \mathrm{z}+\mathrm{s} 1$

Rule 2. If $x$ is $A 2$ and $y$ is $B 2$ and $z$ is $C 2$ then $F 2=p 2 x+q 2$ $\mathrm{y}+\mathrm{r} 2 \mathrm{z}+\mathrm{s} 2$

ANFIS employs back propagation learning to determine the premise parameters and least mean square estimation to determine the consequent parameters.

This algorithm works in two-pass hybrid learning cycles. In the forward pass, the set of premise parameters are fixed and the inputs are propagated to layer 4 , and the set of consequent parameters is computed using least mean square algorithm. In the backward pass, the consequent parameters are fixed and the error signals are propagated backwards and the premise parameters are updated using gradient descent [7].

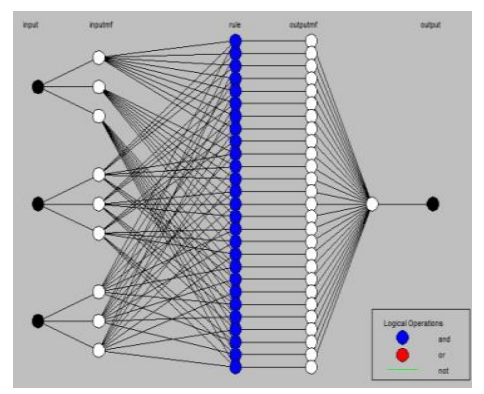

Figure 8. ANFIS architecture

Figure 6 shows the structure of the ANFIS model, which has three inputs, 27 rules and five layers. Function of each layer is briefly described below.

The regression equation of from the taguchi method was obtained as follows.

$\operatorname{Tmax}=16.625+0.00705 * \mathrm{x}+0.03125 * \mathrm{y}+0.125 * \mathrm{z}$

$\mathrm{Fc}=-85+3 * \mathrm{x}+3.5 * \mathrm{y}+5.5 * \mathrm{z}$

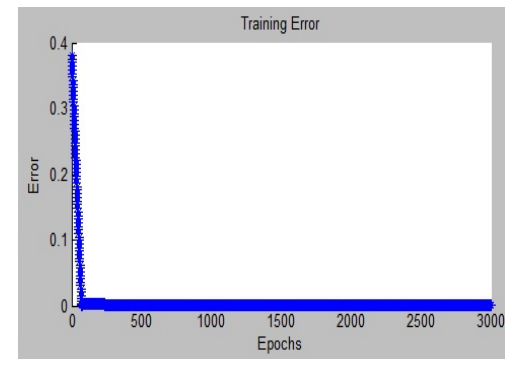

Figure 9. Training error for tmax at 3000 epochs (error. $0.0018697)$

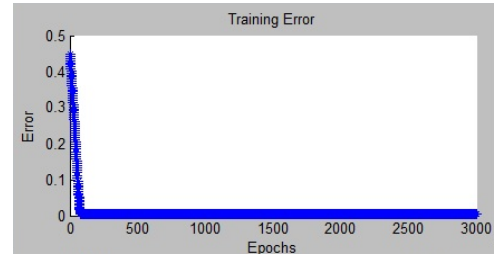

Figure 10. Training error for $\mathrm{Fc}$ at 3000 epochs (error. $0.0018697)$

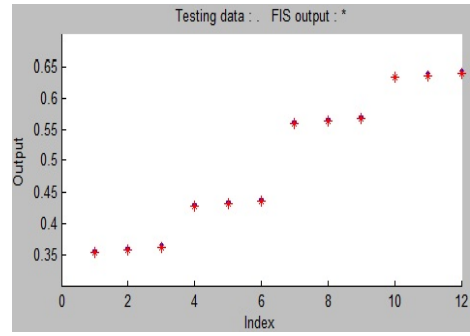

Figure 11. Test error for Tmax (average testing Error 0.0033855)

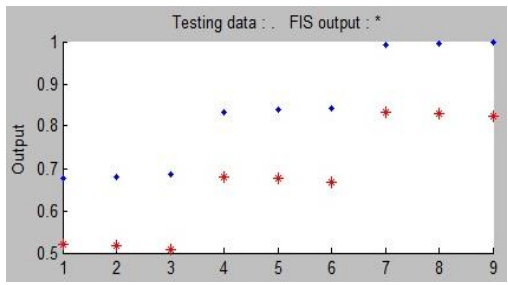

Figure 12. Test error for $\mathrm{Fc}$ (average testing Error 0.16512)

From the Eqn (4) 27 set of training data and 9 set of test data were generated. These data were first normalized and then fitted to the ANFIS model as shown in Figure 6. The analysis was made in MATLAB 7.12.

The training error at 3000 epochs was obtained as 0.0018697 (Figure 7) i.e. $0.19 \%$ and average testing error was obtained as 0.00255966 (Figure 8) i.e. 0.26\%. Both errors were within in acceptable range. The obtained optimum level setting and defuzzified output were $0.333,0.5$, 0.5 and 0.358 respectively. These were coded value. The actual values are as shown in Table 6 . The verification experiment was carried out for the optimum level setting and it has been observed from table 6 that the prediction error is almost $1.09 \%$ which is very small. So, the ANFIS model produces the optimum result which is within acceptable range.

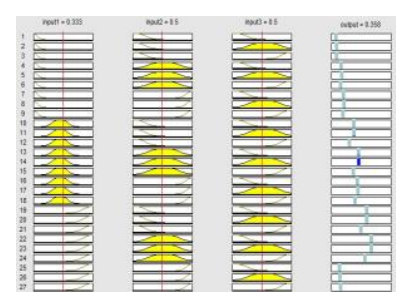

Figure 13. Inputs and output at the final iterations for Tmax

It has been observed from table that $1000 \mathrm{rpm}$ cutting speed, $60 \mathrm{~mm} / \mathrm{min}$ feed rate and $1 \mathrm{~mm}$ depth of cut is the optimum level setting produce by ANFIS model. From the surface graph obtained during final iteration of ANFIS as shown in Figure 10, it has been observed that with cutting speed the variation of output is noticeable. At first it is 
increasing and then it decreased and after the optimum value it increases. Almost same nature is obtained for the other parameters also.

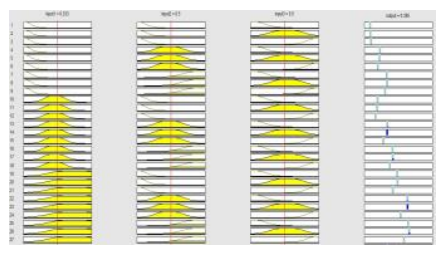

Figure 14. Inputs and output at the final iterations for $\mathrm{Fc}$

Table 7. Optimum parametric combination and verification test

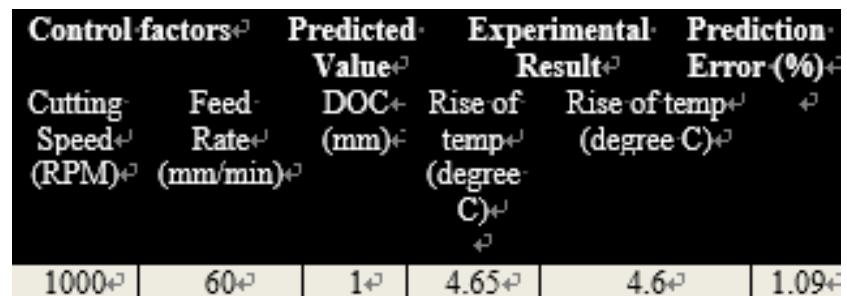

(a) Tmax v/s cutting speed and feed rate
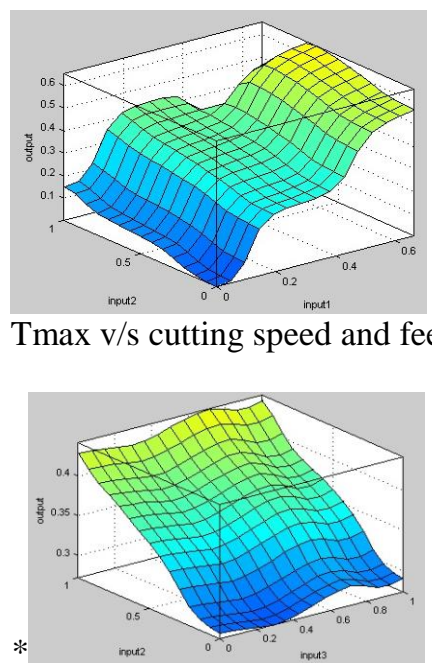

(b) Tmax v/s cutting speed and feed rate

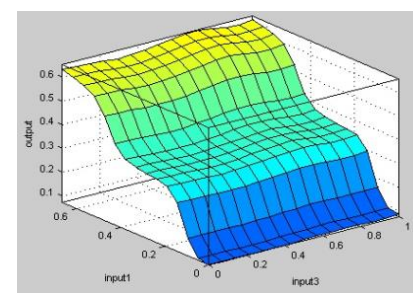

(c) Tmax v/s cutting speed and feed rate

Figure 15. Output i.e. Tmax v/s different inputs at the optimum level setting predicted by ANFIS Model

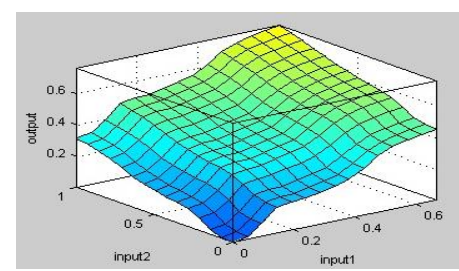

(a) Fc v/s cutting speed and feed rate

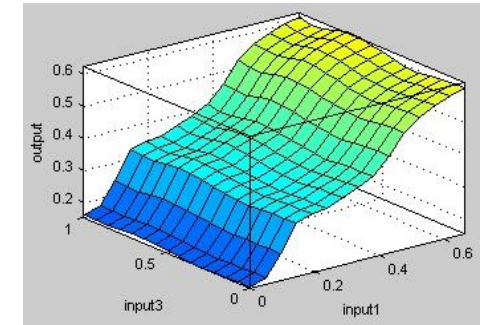

(b) $\mathrm{Fc}$ v/s cutting speed and feed rate

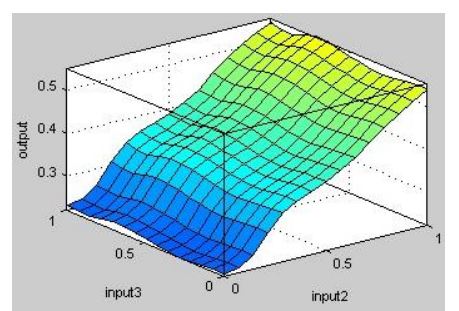

(c)

Fc v/s cutting speed and feed rate

Figure 16. Output i.e. Fc v/s different inputs at the optimum level setting predicted by ANFIS Model

Table 8. Optimum parametric combination and verification test

\begin{tabular}{|c|c|c|c|c|c|}
\hline \multicolumn{3}{|c|}{ Control factors } & Predicted & Experimental & Prediction \\
\hline $\begin{array}{l}\text { Cutting } \\
\text { Speed } \\
\text { (RPM) }\end{array}$ & $\begin{array}{l}\text { Feed } \\
\text { Rate } \\
\text { (mm/min) }\end{array}$ & $\begin{array}{l}\text { DOC } \\
(\mathrm{mm})^{r}\end{array}$ & $\begin{array}{l}\text { Rise of } \\
\text { temp } \\
\text { (degree } \\
\text { C) }\end{array}$ & $\begin{array}{l}\text { Rise of temp } \\
\text { (degree C) }\end{array}$ & + \\
\hline 1000 & 60 & 1 & 35 & 40 & 12.5 \\
\hline
\end{tabular}

\section{CONCLUSIONS}

Carrying the experimental investigation based on Taguchi $\mathrm{L}_{8}$ orthogonal array and followed by ANFIS model approach the following assumption are made.

Prediction of maximum temperature generation at the tool tip is an important phenomenon because it is directly related to energy consumption leading towards sustainability issues.

It has been observed that Taguchi model predict that lowest level setting will produce the minimum tool tip temperature during $\mathrm{CNC}$ turning that is true but in these case 8 data were analyzed. To analyze more data the regression equation was applied.

The generated data were fitted to the ANFIS model and the ANFIS model predict that $1000 \mathrm{rpm}$ cutting speed, 60 $\mathrm{mm} / \mathrm{min}$ feed rate and $1 \mathrm{~mm}$ depth of cut is the optimum level setting that can produce temperature $4.65^{\circ}$ (i.e. difference between tool tip and room temperature) which is very close to experimental result with an error of $1.09 \%$. This method of prediction can be applied for other parameters of the CNC turning also and can help the operator of $\mathrm{CNC}$ machine.

\section{REFERENCES}

[1] Weiser C.R., Vijayraghavan A., Dornfeld D. (2008). Metrics for sustainable manufacturing, Proceeding of the 2008 International Manufacturing Science and Engineering Conference MSEC2008, Illinois, USA. 
[2] Jiang Z., Zhang H., Yan W., Zhoiu M., Li G. (2012). A method for evaluating environmental performance of machining system, Int. Journal of Computer Integrated Manufacturing, Vol. 25, No. 6, pp. 488495. DOI: $10.1080 / 0951192 X .2011 .638323$

[3] Bhanot N., Venkateswara R.P., Deshmukh S.G. (2016). An assessment of sustainability for turning process in an automobile firm, Procedia CIRP, Vol. 48, pp. 538 - 543. DOI: 10.1016/j.procir.2016.03.024

[4] Smith L., Ball P. (2012). Steps towards sustainable manufacturing through modelling material, energy and waste flows, International Journal of Production Economics, Vol. 140, No. 1, pp. 227-238. DOI: 10.1016/j.ijpe.2012.01.036

[5] Muthukrishnan N., Davim J.P. (2009). Optimization of machining parameters of Al/Sic-MMC with ANOVA and ANN analysis, Journal of Material Processing Technology, Vol. 209, pp. 225-232. DOI: 10.1016/j.jmatprotec.2008.01.041

[6] Rao C.J., Sreeamulu D., Mathew A.T. (2014). Analysis of tool life during turning operation by determining optimal process parameters, Procedia Engineering, Vol. 97, pp. 241-250. DOI: 10.1016/j.proeng.2014.12.247

[7] Sadílek M., Dubsk'y J., Sadílková Z., Poruba Z. (2016). Cutting forces during turning depth with variable of cut, Perspectives in Science, Vol. 7, pp. 357-363. DOI: $10.1016 /$ j.pisc.2015.11.055

[8] Wang T.C., Hu X.X., Zhong S.S., Zhang Y.J. (2016). Research on extension knowledge base system for scheme design of mechanical product, Mathematical Modelling of Engineering Problems, Vol. 3, No. 3, pp. 141-145. DOI: 10.18280/mmep.030305
[9] Rajemi M.F., Mativenga P.T., Aramcharoen A. (2010). Sustainable machining. selection of optimum turning conditions based on minimum energy considerations, Journal of Cleaner Production, Vol. 18, pp. 10591065. DOI: $10.1016 /$ j.jclepro.2010.01.025

[10] Madhav S.P. (1989). Matrix experiments using orthogonal arrays, quality engineering using robust design, Prentice Hall, Englewood Cliffs, New Jersey, pp. 41-59.

[11] Kumar S. (2015). Soft computing goes hybrid, neural networks a class room approach, Mc GrawHill Education, India, $2^{\text {nd }}$ Edition, pp. 610-614.

[12] Xia J., Xiao L., Wan L.P. (2016). Application of random-fuzzy probability statistics method, Mathematical Modelling of Engineering Problems, Vol. 3, No. 1, pp. 19-24. DOI: $\underline{10.18280 / \mathrm{mmep} .030103}$

\section{NOMENCLATURE}

$v \quad$ cutting speed in rpm

$f \quad$ feedin $\mathrm{mm} / \mathrm{min}$

$d \quad$ depth of cut in $\mathrm{mm}$

DOE Design of Experiment

ANFIS Adaptive Neuro-Fuzzy System

$\eta \quad$ Signal to noise ratio in $\mathrm{db}$

D.O.F. degree of Freedom

S.O.S. Sum of Square

F Fitness value

$\mathrm{P} \quad$ probability value 